\title{
A study testing the usefulness of a dish-based food-frequency questionnaire developed for epidemiological studies in Korea
}

\author{
Young Ok Kim ${ }^{1}$, Mi Kyung $\mathrm{Kim}^{2} *$, Sang-Ah Lee ${ }^{2}$, Young Mi Yoon ${ }^{2}$ and Satoshi Sasaki ${ }^{3}$ \\ ${ }^{1}$ Department of Food and Nutrition, College of Natural Science, Dongduk Women's University, Seoul, Korea \\ ${ }^{2}$ Division of Carcinogenesis, National Cancer Center, Goyang, Korea \\ ${ }^{3}$ Department of Social and Preventive Epidemiology, School of Public Health, The University of Tokyo, Tokyo, Japan
}

(Received 4 January 2008 - Revised 9 July 2008 - Accepted 14 July 2008 - First published online 12 September 2008)

The purpose of the present study was to test the usefulness of dish items selected in developing a dish-based FFQ (DFFQ) to be used for epidemiological studies in Korea. The dietary data of 6817 subjects from the 2001 Korean National Health and Nutrition Examination Survey were used for the analysis. The $24 \mathrm{~h}$ recall method was employed for the dietary survey. Initially, ninety-five dish items were selected in developing the DFFQ based on consumption frequency, contribution of selected nutrients and coverage of between-person variations. The usefulness of the selected ninety-five dish items was tested based on their degree of contribution in supplying nutrients in the cumulative percentage contribution (cPC), as well as on their degree of explanation for between-person variation in the cumulative regression coefficient (cMRC). According to the results, the ninety-five selected dish items accounted for an average of $92.3 \%$ of seventeen nutrients consumed by the study subjects based on cPC estimation. The top twenty items among the ninety-five dish items covered 70 to $91 \%$ of the between-person variation for the seventeen nutrients based on cMRC estimation. Thus, the results suggest that the ninety-five items would be useful in developing a FFQ for use in epidemiological studies of Koreans, within less than $10 \%$ underestimation.

\section{Food-frequency questionnaires: Epidemiological studies: Korean National Health and Nutrition Examination Survey: Korea}

A epidemiological transition has occurred in Korea, characterised by rapid increases in the incidence and mortality of chronic disease ${ }^{(1)}$. In order to understand the association between diet and chronic disease during this transitional period, there has been an increased demand for both prospective and retrospective epidemiological studies in Korea ${ }^{(2)}$. An important issue in conducting such studies is establishing valid dietary assessment tools for the estimation of average long-term intake of food and nutrients in individuals rather than for precise measurements of absolute dietary intake $^{(3-5)}$. A number of questionnaires, mainly food-based FFQ (FFFQ), have been widely employed in epidemiological studies in both Western countries ${ }^{(6-8)}$ and Asian countries $^{(9,10)}$, including $\operatorname{Korea}^{(11,12)}$. However, the dietary practices of Koreans are quite different from those of Europeans and Americans, which are typically based on the consumption of a single food. Koreans eat many kinds of mixed dishes with various seasonings and cooking oils; thus, a FFFQ is not sufficient to evaluate the effects of the seasonings and cooking oils in the Korean diet. The use of a FFFQ could underestimate the proportion of certain micronutrients, including antioxidant vitamins, fatty acids and phyto-oestrogens. Therefore, the development of a dish-based FFQ (DFFQ) could account for the different dietary practices of Koreans.
The purpose of the present study was to test the usefulness of ninety-five dish items selected in developing a DFFQ for the epidemiological study of Koreans. The 2001 Korean National Health and Nutrition Examination Survey (KNHANES) data were used as representative data from the Korean population.

\section{Materials and methods}

Data source

The dietary data of 6817 subjects aged 20 years and older, from the 2001 KNHANES, were used in the analysis. Detailed information about the 2001 KNHANES is described elsewhere $^{(13,14)}$. In brief, the nationwide KNHANES is conducted every 3 years, and information is collected from a stratified multistage probability sample of South Korean households representing the civilian, non-institutionalised population. The KNHANES is comprised of four parts: the Health Interview Survey, the Health Behavior Survey, the Health Examination Survey, and the Nutrition Survey. There were 246097 primary sampling units, with sixty households in each unit. Sampling units were randomly selected from the primary sampling units using a stratified multistage probability method. A total of 600 sampling units encompassing 13200 households were selected. A total of 37769 subjects

Abbreviations: cPC, cumulative percentage contribution; DFFQ, dish-based FFQ; FFFQ, food-based FFQ; KNHANES, Korean National Health and Nutrition Examination Survey.

* Corresponding author: Mi Kyung Kim, fax +82 31920 2006, email alrud@ncc.re.kr 
(aged 1 year and older) from the 13200 households were selected and participated in the Health Interview Survey. The remaining three surveys were conducted on randomly selected 200 sampling units encompassing 4015 households from the original 600 sampling units. All household members participating in the remaining three surveys were examined to determine health status, and were interviewed for the dietary survey using a $24 \mathrm{~h}$ dietary recall (9968 subjects).

The $24 \mathrm{~h}$ dietary recall questionnaire requested detailed descriptions of the type and amount of all foods consumed on the day before the interview, including snacks, beverages, and ingredient information for all sauces and condiments. Additionally, information regarding the time and the place of each meal was recorded. Subjects were also asked to assess whether or not the time period in question represented typical dietary intake. If it was not a typical day (for example, birthday party, family gathering, eating at a restaurant), the subjects were asked to report $2 \mathrm{~d}$ before the interview date, or the most recent typical day. The $24 \mathrm{~h}$ dietary recall began with the first meal or beverage consumed at waking until midnight of the reporting day. Trained dietitians administered the $24 \mathrm{~h}$ dietary recall using measuring cups, portion-size booklets and photographs. All completed records were checked by a research dietitian for accuracy. Nutrient intake of each food item was calculated using the Diet Analysis program (version 4.0; Nutritional Epidemiology Laboratory, National Cancer Center) for a total of seventeen nutrients (total energy, protein, fat, carbohydrate, fibre, $\mathrm{Ca}, \mathrm{P}, \mathrm{Fe}, \mathrm{Na}, \mathrm{K}$, vitamin $\mathrm{A}$, retinol, carotene, vitamin $B_{1}$, vitamin $B_{2}$, niacin and vitamin $C$ ). Nutrient intake was calculated based on the 5th Edition Food Composition Table ${ }^{(15)}$ and a database of processed and fast foods ${ }^{(16)}$. Individuals aged less than 20 years $(2990$ subjects) and individuals with extreme total energy intake (defined as $2.93-25.1 \mathrm{MJ} / \mathrm{d}$ for males and $2.51-16.7 \mathrm{MJ} / \mathrm{d}$ for females) (forty males and 121 females) were excluded, resulting in 6817 study participants for the analysis.

Initial selection of the ninety-five dish items for developing the dish-based food-frequency questionnaire

The selection of the dish items was implemented using Willett's method ${ }^{(5)}$, with the $24 \mathrm{~h}$ dietary recall data of the 2001 KNHANES $^{(13)}$, and is described by flow chart in Fig. 1. For the initial selection of foods items contributing to total nutrient intake, the contribution analysis was performed. The percentage contribution of each nutrient by the 629 dishes was computed as the arithmetic mean of the individual percentage contribution of each nutrient by dish. The 411 dish items that were selected accounted for $90 \%$ of the cumulative percentage contribution (cPC). Multiple regression analysis (MRA) was performed with the total intake of each nutrient as the dependent variable and the overall amounts of each nutrient from each of the 411 items as the independent variables for each participant. This estimated the degree of explanation of between-person variation. The items were selected until the cumulative multiple regression coefficients (cumulative partial $R^{2}$ ) reached $0 \cdot 90$. Finally, similar dishes were aggregated into groups based on the nutrient content per portion eaten, the cooking method and the food ingredients in the dish; they were coordinated when a name, a main
$1 \mathrm{~d} 24 \mathrm{~h}$ recall from the 2001 KNHANES ( $n$ 9968)

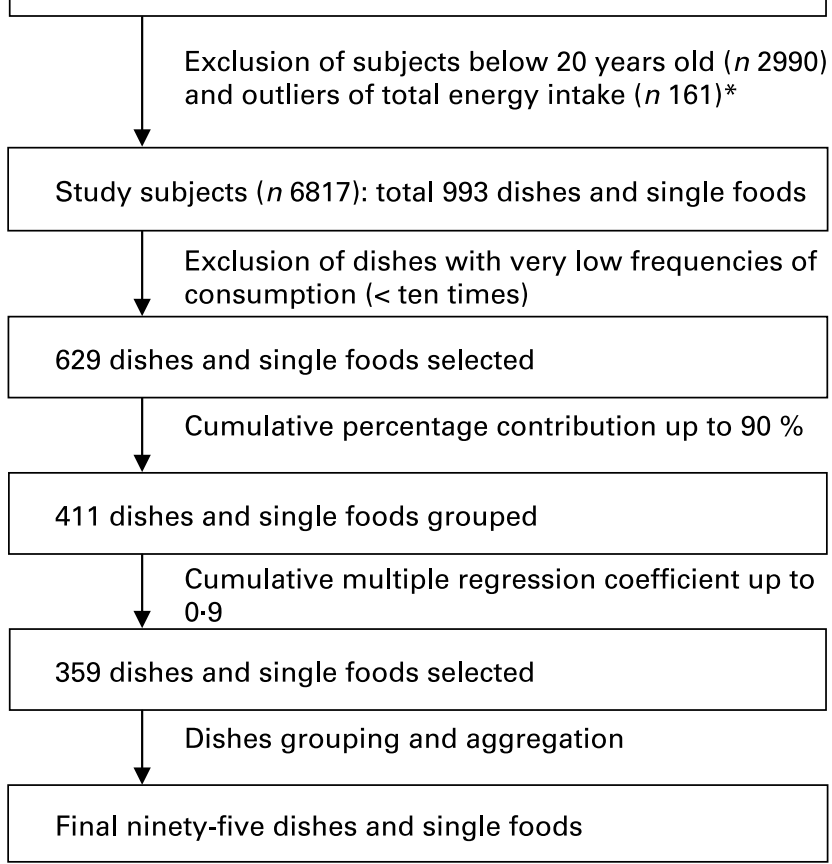

Fig. 1. Flow chart for the selection of dish and food items from the 2001 Korean National Health and Nutrition Examination Survey (KNHANES). *Males 2930-25100 kJ/d (700-6000 kcal/d); females $2510-16740 \mathrm{~kJ} / \mathrm{d}$ $(600-4000 \mathrm{kcal} / \mathrm{d})$

food ingredient, or more than $90 \%$ of recipe ingredients for a dish were similar to another dish. Several seasonal food items, for example, seasonal fruits (strawberry, watermelon, etc.) and celebration foods, were not covered by the survey period of the 2001 KNHANES, but were included in the DFFQ. The composition values of the dishes were derived from standard recipes based on a publication by the Korean Ministry of Health and Welfare ${ }^{(16)}$.

\section{Statistical approach}

The comparison of general characteristics between males and females was performed using the $t$ test for continuous variables and the $\chi^{2}$ test for categorical variables. Stepwise regression models were used to determine the list of dishes to be included in the DFFQ, taking into consideration the between-person variability added by each item ${ }^{(5)}$. The data processing was carried out using SAS (version 8.0; SAS Institute Inc., Cary, NC, USA) statistical software.

\section{Results}

\section{Characteristics of study subjects}

The characteristics of the study subjects (3158 men and 3659 women) are shown in Table 1 . The mean age of the male subjects was 43.7 years and that of the female subjects was 44.9 years. The residential areas of the subjects were categorised as metropolitan city $(46.6 \%)$, middle or small city $(30.7 \%)$ and rural $(22.7 \%)$. Among the study subjects, $37.7 \%$ of the men and $23.5 \%$ of the women had education levels of more than 
Table 1. Distribution of age, residential area, education and nutrient intake level of study subjects by sex (Mean values and standard deviations or numbers and percentages)

\begin{tabular}{|c|c|c|c|c|c|c|c|}
\hline \multirow[b]{2}{*}{ Variables } & \multicolumn{2}{|c|}{ Male ( $n$ 3158) } & \multicolumn{2}{|c|}{ Female ( $n$ 3659) } & \multirow[b]{2}{*}{$P^{*}$} & \multicolumn{2}{|c|}{ Total $(n 6817)$} \\
\hline & Mean & SD & Mean & SD & & Mean & SD \\
\hline $\begin{array}{l}\text { Age (years) } \\
20-29\end{array}$ & 43.7 & $14 \cdot 6$ & $44 \cdot 9$ & $16 \cdot 0$ & $<0.0001$ & $44 \cdot 3$ & $15 \cdot 4$ \\
\hline$n$ & \multicolumn{2}{|c|}{553} & \multicolumn{2}{|c|}{668} & & \multicolumn{2}{|c|}{1221} \\
\hline$\%$ & \multicolumn{2}{|c|}{17.5} & \multicolumn{2}{|c|}{$18 \cdot 3$} & & \multicolumn{2}{|c|}{$17 \cdot 9$} \\
\hline \multicolumn{8}{|l|}{$30-39$} \\
\hline$n$ & \multicolumn{2}{|c|}{851} & \multicolumn{2}{|c|}{923} & & \multicolumn{2}{|c|}{1774} \\
\hline$\%$ & \multicolumn{2}{|c|}{$27 \cdot 0$} & \multicolumn{2}{|c|}{$25 \cdot 2$} & & \multicolumn{2}{|c|}{$26 \cdot 0$} \\
\hline $40-49$ & & & & & & & \\
\hline$n$ & & & & & & & \\
\hline$\%$ & & & & & & & \\
\hline $50-59$ & & & & & & & \\
\hline$n$ & & & & & & & \\
\hline$\%$ & & & & & & & \\
\hline $60-69$ & & & & & & & \\
\hline$n$ & & & & & & & \\
\hline$\%$ & & & & & & & \\
\hline $70+$ & & & & & & & \\
\hline$n$ & & & & & & & \\
\hline$\%$ & & & & & & & \\
\hline Region & & & & & 0.8592 & & \\
\hline Metropolitan city & & & & & & & \\
\hline$n$ & & & & & & & \\
\hline$\%$ & & & & & & & \\
\hline Middle or small c & & & & & & & \\
\hline$n$ & & & & & & & \\
\hline$\%$ & & & & & & & \\
\hline Rural & & & & & & & \\
\hline$n$ & & & & & & & \\
\hline$\%$ & & & & & & & \\
\hline Education & & & & & $<0.0001$ & & \\
\hline$\leq 12$ years & & & & & & & \\
\hline$n$ & & & & & & & \\
\hline$\%$ & & & & & & & \\
\hline$>12$ years & & & & & & & \\
\hline$n$ & & & & & & & \\
\hline$\%$ & & & & & & & \\
\hline Energy (kJ) & 9749 & 3655 & 7555 & 2676 & $<0.0001$ & 8572 & 3351 \\
\hline Protein (g) & $86 \cdot 7$ & 43.8 & 64.5 & $32 \cdot 0$ & $<0.0001$ & 74.8 & 39.5 \\
\hline Fat $(\mathrm{g})$ & $46 \cdot 0$ & $36 \cdot 0$ & 33.1 & $25 \cdot 6$ & $<0.0001$ & 39.1 & 31.5 \\
\hline Carbohydrate (g) & 363 & 133 & 304 & 107 & $<0.0001$ & 331 & 123 \\
\hline Fibre $(\mathrm{g})$ & 8.25 & 4.62 & $7 \cdot 20$ & $4 \cdot 31$ & $<0.0001$ & 7.69 & 4.49 \\
\hline $\mathrm{Ca}(\mathrm{mg})$ & 556 & 360 & 471 & 304 & $<0.0001$ & 510 & 334 \\
\hline$P(\mathrm{mg})$ & 1391 & 591 & 1081 & 449 & $<0.0001$ & 1224 & 542 \\
\hline $\mathrm{Fe}(\mathrm{mg})$ & $14 \cdot 8$ & 9.08 & $12 \cdot 1$ & $9 \cdot 45$ & 0.018 & 13.4 & $9 \cdot 38$ \\
\hline $\mathrm{Na}(\mathrm{mg})$ & 6116 & 3342 & 5023 & 3169 & 0.002 & 5529 & 3295 \\
\hline $\mathrm{K}(\mathrm{mg})$ & 3363 & 1552 & 2820 & 1417 & $<0.0001$ & 3072 & 1505 \\
\hline Vitamin A (R.E.) & 757 & 1081 & 603 & 657 & $<0.0001$ & 674 & 883 \\
\hline Retinol $(\mu \mathrm{g})$ & 97.9 & 791 & $62 \cdot 7$ & 228 & $<0.0001$ & $79 \cdot 0$ & 564 \\
\hline Carotene $(\mu \mathrm{g})$ & 3752 & 4271 & 3040 & 3352 & $<0.0001$ & 3370 & 3822 \\
\hline Vitamin $B_{1}(\mathrm{mg})$ & 1.47 & 0.87 & $1 \cdot 16$ & 0.68 & $<0.0001$ & 1.30 & 0.79 \\
\hline Vitamin $B_{2}(\mathrm{mg})$ & 1.29 & 0.78 & 1.01 & 0.55 & $<0.0001$ & $1 \cdot 14$ & 0.68 \\
\hline Niacin $(\mathrm{mg})$ & $20 \cdot 8$ & 11.9 & $15 \cdot 7$ & $9 \cdot 17$ & $<0.0001$ & $18 \cdot 1$ & $10 \cdot 8$ \\
\hline Vitamin C (mg) & 136 & 111 & 149 & 125 & $<0.0001$ & 143 & 119 \\
\hline
\end{tabular}

R.E., retinol equivalents.

${ }^{\star} P$ values for comparison between sex by $t$ test.

12 years. The BMI for the men and women were 23.7 and $23.4 \mathrm{~kg} / \mathrm{m}^{2}$, respectively.

Selected ninety-five dish items for developing the dish-based food-frequency questionnaire

The initial analysis yielded a total of 993 dish items consumed by the 6817 participants. Dishes with very low frequencies of consumption were excluded ( $n$ 364) and dishes with minimal contribution to the dietary acquisition of the aforementioned seventeen nutrients ( $n$ 218) were excluded. This left a final count of 411 dishes, which accounted for $90 \%$ of the cPC. The next stage of selection among the 411 items was carried out based on the degree of explanation for between-person variation. Therefore, 359 dish items were retained. Finally, after grouping and aggregation of 359 dishes, a total of 
ninety-five dish items were selected for the DFFQ (Fig. 1). The publication categories ${ }^{(16)}$ of the ninety-five dish items included (Table 2) in the DFFQ were rice and cereals (seven items), noodles (three items), breads (seven items), soups or stews (eleven items), fish and shellfish (ten items), meats (ten items), eggs (two items), pulses (three items), vegetables (thirteen items), kimchies (six items), milk and milk products (two items), fruits (six items), beverages (nine items) and snacks (six items).

\section{Intake frequency and portion size}

The food intake frequency in the semi-quantitative FFQ was classified into nine categories: almost never, once per month, two or three times per month, once or twice times per week, three or four times per week, five or six times per week, once per $\mathrm{d}$, twice per $\mathrm{d}$, and three times per $\mathrm{d}$. In short, the standard portion size of each dish item per meal was determined using the mean amount, the typical or standard value, or the natural unit and also referred to the Korean Ministry of Health and Welfare portion-size booklet ${ }^{(16)}$. Portion size in the semi-quantitative FFQ was divided into three categories: small (half the medium portion), medium and large (1.5 times or greater than the medium portion). The medium intake was determined as the mean amount from the study subjects. For an example of the semi-quantitative FFQ, see the Appendix.

\section{Usefulness of a diet-based food-frequency questionnaire}

We wished to quantify the usefulness of the ninety-five selected dishes and the top twenty items in explaining between-person variations in nutrient consumption for energy and nutrients as estimated by cumulative multiple regression coefficient $\left(R^{2}\right)$ and the coverage of total nutrient consumption as estimated by cPC (\%) (Table 2).

The top twenty dish items accounted for 77, 70, 91 and $82 \%$ of the between-person variation for total energy, protein, carbohydrate and fat intake, respectively. Among the twenty items, rice, the main staple for Korean people, was shown to account for 32 and $52 \%$ of the between-person variation for total energy and carbohydrate intake, respectively. Rice also covered 45.3 and $59.7 \%$ of the total intake of energy and carbohydrate, respectively. Roasted pork, spicy pan-fried pork and roasted beef accounted for $45 \%$ of the betweenperson variation of fat intake.

A relatively limited number of dish items can explain the $>90 \%$ of the between-person variation of vitamins, compared with those of macronutrients and minerals. Only one item accounted for 96 and $79 \%$ of the between-person variation for retinol (grilled fatty fish) and vitamin C (orange-coloured fruit) intake. Furthermore, the top twelve items reached almost $100 \%$ of the between-person variation for retinol, and between seven and sixteen items reached $90 \%$ of the between-person variation for vitamin $\mathrm{C}$ and carotene, respectively. Grilled fatty fish accounted for $96 \%$ of the between-person variation for retinol. The analysis suggested that the top twelve dish items were sufficient enough to cover $100 \%$ of the between-person variation.
The top twenty dish items accounted for $85,67,81,83$ and $71 \%$ of the between-person variations for total intakes of $\mathrm{Ca}$, $\mathrm{P}, \mathrm{Fe}, \mathrm{Na}$ and $\mathrm{K}$, respectively. Soyabean paste soup was the top contributor in terms of $\mathrm{Ca}$ and $\mathrm{Fe}$ intake, and the major contributors to $\mathrm{Na}$ intake were Korean cabbage kimchi, radish kimchi and soyabean paste stew (Table 2).

The number of dish items required to meet the $90 \%$ of consumed foods as well as the between-person variation of the seventeen nutrients are listed in Table 3. The number of items that covered $90 \%$ of the total intake of each nutrient, as estimated by $\mathrm{cPC}$, varied from thirty-three for vitamin $\mathrm{C}$ to seventy-two for retinol. The number of items that accounted for $90 \%$ of the between-person variability also varied from one for retinol to forty-one for $\mathrm{K}$.

Table 4 summarises the values of the ninety-five selected dish items in terms of coverage of total nutrient intake and between-person variation. The ninety-five selected items covered an average of $92.3 \%$ of the intake of the seventeen nutrients by the study subjects, ranging from $88.6 \%$ for retinol to $95.4 \%$ for vitamin $\mathrm{C}$. The ninety-five items could also explain $99.9 \%$ of the between-person variation for the consumption of the seventeen nutrients in the study subjects.

\section{Discussion}

The major functions of a rational FFQ are whether it is a useful tool for measuring average long-term dietary intake and for ranking the typical nutrient intakes of individuals. It does not precisely estimate the absolute consumption of nutrients for an entire study population. The use of a food item must vary from person to person for food discrimination according to dietary intake. A more important issue in the design of FFQ is the selection of food items with high between-person variations identified through multiple regression analyses for each nutrient compared with the total nutrient intake in order to identify food items with the most discrimination. Recently, many dietary assessment questionnaires ${ }^{(12,17,18)}$ have been developed and several among them were validated for use in Korea ${ }^{(11,19)}$ Nevertheless, most existing FFFQ ${ }^{(12)}$ with a few exceptions ${ }^{(11)}$ lacked the appropriate analyses for food discrimination. In compiling a food list of FFQ, the food consumed frequently by Koreans and the foods with substantial nutrient content were selected based on the data of the Report on the National Nutrition Survey ${ }^{(20)}$. However, selection of foods was not based on between-person variations.

A DFFQ could have advantages over the several FFFQ developed and validated in Korea ${ }^{(11,12,17,18)}$, as it could include ingredients such as seasonings, spices and cooking oils. This would allow for a more accurate calculation of nutrient intake, especially for micronutrients such as antioxidant vitamins, phytochemicals and fatty acids. The relatively low coverage rates of FFFQ were most likely secondary to a food list that did not include seasonings and oils, which are among the main sources of fat, $\mathrm{Na}$ and $\beta$-carotene in the Korean $\operatorname{diet}^{(12,21)}$. The estimated coverage of the intake of seventeen nutrients selected by this DFFQ was much higher (92.3\% overall, ranging from 88.6 to $95.4 \%$ ) than those of FFFQ $^{(9,12)}$. Additionally, our DFFQ was developed on the basis of national representative data (KNHANES) with a substantially larger sample size (6817 subjects) as compared 
WS British Journal of Nutrition

\begin{tabular}{|c|c|c|c|c|c|c|c|c|c|c|c|c|c|}
\hline \multirow[b]{3}{*}{ Composite no. } & \multirow[b]{3}{*}{ Dish name } & \multicolumn{4}{|c|}{ Energy } & \multicolumn{4}{|c|}{ Retinol } & \multicolumn{4}{|c|}{$\mathrm{Na}$} \\
\hline & & \multicolumn{2}{|c|}{ MRC } & \multicolumn{2}{|r|}{ PC } & \multicolumn{2}{|c|}{ MRC } & \multicolumn{2}{|r|}{ PC } & \multicolumn{2}{|c|}{ MRC } & \multicolumn{2}{|r|}{ PC } \\
\hline & & $R^{2}$ & Ranking* & $\%$ & Ranking* & $R^{2}$ & Ranking* & $\%$ & Ranking* & $R^{2}$ & Ranking* & $\%$ & Ranking* \\
\hline \multicolumn{14}{|l|}{ Staple foods } \\
\hline 1 & Cooked rice & 0.144 & 1 & 29.7 & 1 & 0.000 & & 0.11 & & 0.001 & & 1.95 & 12 \\
\hline 2 & Cooked rice with cereals & 0.091 & 2 & $12 \cdot 9$ & 2 & 0.000 & & 0.07 & & 0.001 & & 0.76 & \\
\hline 3 & Rice gruels & 0.010 & & 0.37 & & 0.000 & & 0.23 & & 0.006 & & 0.25 & \\
\hline 4 & Rice topped with vegetable or meat & 0.017 & 15 & 0.82 & 18 & 0.001 & 9 & 2.58 & 8 & 0.006 & & 0.59 & \\
\hline 5 & Rice rolled in laver & 0.086 & 3 & $2 \cdot 76$ & 5 & 0.002 & 5 & $5 \cdot 20$ & 4 & 0.011 & 20 & 1.37 & 15 \\
\hline 6 & Noodles & 0.042 & 6 & 1.91 & 9 & 0.000 & 20 & 1.74 & 12 & 0.053 & 5 & 3.61 & 6 \\
\hline 7 & Udong, spaghetti & 0.042 & 5 & $2 \cdot 26$ & 8 & 0.000 & 15 & 1.27 & 18 & 0.018 & 13 & 2.01 & 11 \\
\hline 8 & Ramyeon (instant noodles) & 0.039 & 7 & $2 \cdot 68$ & 6 & 0.000 & 14 & 2.47 & 9 & 0.022 & 11 & 3.25 & 8 \\
\hline 9 & Rice cake soup, dumpling soup & 0.019 & 12 & 0.94 & 15 & 0.000 & & 1.29 & 17 & 0.009 & & 0.94 & \\
\hline 10 & Loaf bread, toast, sandwich & 0.003 & & 0.20 & & 0.003 & 4 & 1.78 & 11 & 0.000 & & 0.04 & \\
\hline 11 & Powder of roasted grain, cereals & 0.010 & & 0.46 & & 0.000 & 17 & 0.66 & & 0.001 & & 0.16 & \\
\hline \multicolumn{14}{|c|}{ 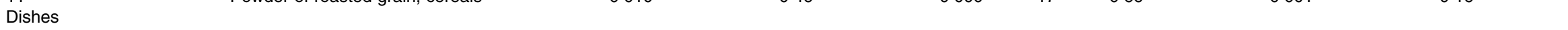 } \\
\hline 16 & Pizza, hamburger & 0.017 & 16 & 0.49 & & 0.001 & 13 & 1.39 & 16 & 0.002 & & 0.31 & \\
\hline 17 & Fried potato chips & 0.000 & & 0.00 & & 0.000 & & 0.00 & & 0.000 & & 0.00 & \\
\hline 18 & Broth (vegetable, potato) & 0.002 & & 0.27 & & 0.000 & 19 & $1 \cdot 16$ & 20 & 0.013 & 14 & 1.59 & 13 \\
\hline 19 & Soyabean paste soup & 0.003 & & 1.02 & 14 & 0.001 & 11 & 0.46 & & 0.024 & 9 & 4.64 & 4 \\
\hline 20 & Meat soup & 0.005 & & 0.79 & 19 & 0.000 & & 0.68 & & 0.086 & 3 & 3.70 & 5 \\
\hline 21 & Fish soup & 0.003 & & 0.42 & & 0.000 & & 1.08 & & 0.013 & 15 & 1.29 & 16 \\
\hline 22 & Boiled bone stew & 0.012 & 18 & 0.89 & 16 & 0.000 & & 1.73 & 13 & 0.021 & 12 & $1 \cdot 19$ & 18 \\
\hline 23 & Spicy beef soup with various condiments & 0.004 & & 0.47 & & 0.000 & 16 & $1 \cdot 11$ & & 0.011 & 19 & 0.97 & \\
\hline 24 & Soyabean paste stew & 0.004 & & 0.41 & & 0.000 & & 0.18 & & 0.006 & & 0.52 & \\
\hline 25 & Kimchi stew & 0.004 & & 0.74 & & 0.024 & 2 & 6.53 & 3 & 0.012 & 16 & 1.54 & 14 \\
\hline 26 & Meat stew & 0.007 & & $1 \cdot 15$ & 12 & 0.000 & & 0.43 & & 0.024 & 8 & 3.52 & 7 \\
\hline 27 & Fish stew & 0.005 & & 1.23 & 11 & 0.000 & & 0.07 & & 0.058 & 4 & 5.48 & 3 \\
\hline 28 & Tofu stew & 0.002 & & 0.22 & & 0.000 & & 0.91 & & 0.009 & & 0.35 & \\
\hline 29 & Braised non-fatty fish & 0.003 & & 0.29 & & 0.000 & & 0.63 & & 0.012 & 17 & 0.64 & \\
\hline 30 & Broiled non-fatty fish & 0.009 & & 0.51 & & 0.000 & & 0.70 & & 0.007 & & 0.79 & \\
\hline 31 & Pan-fried non-fatty fish fillet & 0.008 & & 0.40 & & 0.000 & & 0.80 & & 0.002 & & 0.31 & \\
\hline 32 & Raw non-fatty fish & 0.006 & & 0.34 & & 0.000 & & 0.60 & & 0.006 & & 0.42 & \\
\hline 33 & Braised fatty fish & 0.004 & & 0.36 & & 0.000 & & 0.85 & & 0.004 & & 0.38 & \\
\hline 34 & Broiled fatty fish & 0.011 & 20 & 0.36 & & 0.956 & 1 & 17.9 & 1 & 0.010 & & 0.79 & \\
\hline 35 & Raw fatty fish & 0.000 & & 0.00 & & 0.000 & & 0.00 & & 0.000 & & 0.00 & \\
\hline 36 & Braised anchovies/dried small shrimp & 0.002 & & 0.39 & & 0.000 & & 0.03 & & 0.003 & & 0.60 & \\
\hline 37 & Pan-fried cuttlefish seasoned with red pepper & 0.002 & & 0.37 & & 0.000 & & 0.04 & & 0.006 & & 0.81 & \\
\hline 38 & Spicy steamed cuttlefish with vegetable & 0.001 & & $0 \cdot 10$ & & 0.000 & & 0.02 & & 0.001 & & 0.18 & \\
\hline 39 & Roasted beef with seasoning & 0.004 & & 0.16 & & 0.000 & & 0.30 & & 0.002 & & 0.18 & \\
\hline 40 & Pan-fried beef with seasoning & 0.002 & & 0.16 & & 0.000 & & 0.14 & & 0.001 & & 0.14 & \\
\hline 41 & Braised beef with seasoning & 0.018 & 14 & 0.45 & & 0.000 & & 0.39 & & 0.005 & & 0.31 & \\
\hline 42 & Roasted pork with seasoning & 0.012 & 17 & 0.53 & & 0.000 & & 0.40 & & 0.004 & & 0.45 & \\
\hline 43 & Spicy pan-fried pork & 0.033 & 8 & 1.66 & 10 & 0.000 & & 1.45 & 15 & 0.007 & & $1 \cdot 13$ & 20 \\
\hline 44 & Braised pork & 0.072 & 4 & $2 \cdot 28$ & 7 & 0.000 & & $1 \cdot 10$ & & 0.005 & & 0.54 & \\
\hline 45 & Ham, sausage & 0.002 & & 0.20 & & 0.000 & & 0.25 & & 0.001 & & 0.24 & \\
\hline 46 & Whole chicken soup & 0.010 & & 0.28 & & 0.001 & 10 & 1.47 & 14 & 0.006 & & 0.31 & \\
\hline 47 & Seasoned and simmered chicken & 0.009 & & 0.42 & & 0.001 & 8 & 2.79 & 7 & 0.005 & & 0.43 & \\
\hline 48 & Stir-fried chicken & 0.010 & & 0.41 & & 0.001 & 12 & 1.92 & 10 & 0.003 & & 0.29 & \\
\hline 49 & Steamed egg & 0.001 & & 0.17 & & 0.002 & 6 & 4.57 & 5 & 0.002 & & 0.29 & \\
\hline 50 & Fried eggs & 0.005 & & 0.60 & & 0.001 & 7 & 3.40 & 6 & 0.002 & & 0.54 & \\
\hline
\end{tabular}


WS British Journal of Nutrition

Table 2. Continued

\begin{tabular}{|c|c|c|c|c|c|c|c|c|c|c|c|c|c|}
\hline \multirow[b]{3}{*}{ Composite no. } & \multirow[b]{3}{*}{ Dish name } & \multicolumn{4}{|c|}{ Energy } & \multicolumn{4}{|c|}{ Retinol } & \multicolumn{4}{|c|}{$\mathrm{Na}$} \\
\hline & & \multicolumn{2}{|c|}{ MRC } & \multicolumn{2}{|c|}{ PC } & \multicolumn{2}{|c|}{ MRC } & \multicolumn{2}{|r|}{$\mathrm{PC}$} & \multicolumn{2}{|c|}{ MRC } & \multicolumn{2}{|r|}{ PC } \\
\hline & & $R^{2}$ & Ranking* & $\%$ & Ranking* & $R^{2}$ & Ranking* & $\%$ & Ranking ${ }^{*}$ & $R^{2}$ & Ranking* & $\%$ & Ranking* \\
\hline 51 & Soyabean curds & 0.002 & & 0.25 & & 0.000 & & $0 \cdot 10$ & & 0.002 & & 0.29 & \\
\hline 52 & Soyabean milk & 0.001 & & 0.12 & & 0.000 & & 0.00 & & 0.001 & & 0.16 & \\
\hline 53 & Soyabean boiled with soya sauce & 0.000 & & 0.00 & & 0.000 & & 0.00 & & 0.000 & & 0.00 & \\
\hline 54 & Vegetable pancake & 0.009 & & 0.25 & & 0.000 & & 0.22 & & 0.009 & & 0.39 & \\
\hline 55 & Stir-fried vegetable & 0.008 & & 0.39 & & 0.000 & & 0.05 & & 0.024 & 10 & 0.94 & \\
\hline 56 & Braised vegetable with soya sauce & 0.006 & & 0.17 & & 0.000 & & 0.15 & & 0.000 & & 0.04 & \\
\hline 57 & Deep-fried vegetables & 0.001 & & 0.09 & & 0.000 & & 0.00 & & 0.001 & & 0.16 & \\
\hline 58 & Cooked green and yellow vegetable & 0.001 & & 0.31 & & 0.000 & & 0.00 & & 0.003 & & 0.68 & \\
\hline 59 & Green and yellow vegetable & 0.000 & & 0.09 & & 0.000 & & 0.00 & & 0.001 & & 0.12 & \\
\hline 60 & Cooked white vegetable & 0.001 & & 0.37 & & 0.000 & & 0.00 & & 0.009 & & 1.14 & 19 \\
\hline 61 & Cruciferous vegetable & 0.001 & & 0.28 & & 0.000 & & 0.04 & & 0.012 & 18 & 1.23 & 17 \\
\hline 62 & Acorn starch jelly, mung bean jelly & 0.000 & & 0.06 & & 0.000 & & 0.00 & & 0.001 & & 0.13 & \\
\hline 63 & Mushrooms & 0.001 & & 0.09 & & 0.000 & & 0.11 & & 0.000 & & 0.12 & \\
\hline 64 & Salad (vegetable and fruits) & 0.003 & & 0.30 & & 0.000 & & 0.25 & & 0.000 & & 0.09 & \\
\hline 65 & Toasted laver & 0.001 & & 0.16 & & 0.000 & & 0.00 & & 0.004 & & 0.38 & \\
\hline 66 & Seaweeds & 0.000 & & 0.10 & & 0.000 & & 0.00 & & 0.005 & & 0.47 & \\
\hline 67 & Korean cabbage kimchi & 0.000 & & 0.76 & & 0.000 & & 0.00 & & 0.162 & 2 & $18 \cdot 2$ & 1 \\
\hline 68 & Radish kimchi & 0.001 & & 0.48 & & 0.000 & & 0.01 & & 0.191 & 1 & 8.62 & 2 \\
\hline 69 & Other kimchi & 0.000 & & 0.17 & & 0.000 & & 0.00 & & 0.034 & 6 & 2.73 & 9 \\
\hline 70 & Pickled vegetables & 0.000 & & 0.12 & & 0.000 & & 0.04 & & 0.033 & 7 & 2.08 & 10 \\
\hline 71 & Seasoned crab & 0.000 & & 0.06 & & 0.000 & & 0.01 & & 0.003 & & 0.26 & \\
\hline 72 & Salt-fermented fish & 0.000 & & 0.06 & & 0.000 & & 0.00 & & 0.005 & & 0.47 & \\
\hline 92 & Potatoes and starches (potato, sweet potato) & 0.011 & 19 & 0.77 & 20 & 0.000 & & 0.08 & & 0.003 & & 0.43 & \\
\hline \multicolumn{14}{|c|}{ 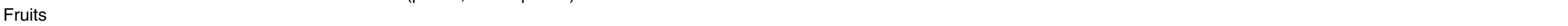 } \\
\hline 75 & Orange-coloured fruits (orange, persimmon) & 0.026 & 10 & 2.93 & 4 & 0.000 & & 0.00 & & 0.000 & & 0.17 & \\
\hline 76 & Red-coloured fruits (strawberry, apple) & 0.008 & & 0.89 & 17 & 0.000 & & 0.00 & & 0.000 & & 0.02 & \\
\hline 77 & Green-coloured fruits (melon, kiwi) & 0.000 & & 0.02 & & 0.000 & & 0.00 & & 0.000 & & 0.00 & \\
\hline 78 & White-coloured fruits (banana, white peach) & 0.005 & & 0.59 & & 0.000 & & 0.00 & & 0.001 & & 0.06 & \\
\hline 79 & Purple-coloured fruits (grapes, plum) & 0.000 & & 0.05 & & 0.000 & & 0.00 & & 0.000 & & 0.03 & \\
\hline 80 & Tomato, cherry tomato & 0.000 & & 0.00 & & 0.000 & & 0.00 & & 0.000 & & 0.00 & \\
\hline \multicolumn{14}{|c|}{ Dairy food and beverages } \\
\hline 73 & Milk & 0.018 & 13 & 1.05 & 13 & 0.004 & 3 & 11.5 & 2 & 0.001 & & 0.35 & \\
\hline 74 & Milk products & 0.003 & & 0.38 & & 0.000 & 18 & 1.26 & 19 & 0.000 & & 0.11 & \\
\hline 81 & Tea & 0.004 & & 0.18 & & 0.000 & & 0.00 & & 0.000 & & 0.01 & \\
\hline 82 & Coffee & 0.028 & 9 & 3.67 & 3 & 0.000 & & 0.11 & & 0.000 & & 0.33 & \\
\hline 83 & Carbonated beverages & 0.002 & & 0.33 & & 0.000 & & 0.00 & & 0.000 & & 0.01 & \\
\hline 84 & Korean traditional beverages & 0.001 & & 0.17 & & 0.000 & & 0.01 & & 0.000 & & 0.01 & \\
\hline 85 & Beer & 0.006 & & 0.19 & & 0.000 & & 0.00 & & 0.000 & & 0.01 & \\
\hline 86 & Soju & 0.021 & 11 & 0.62 & & 0.000 & & 0.00 & & 0.000 & & 0.03 & \\
\hline 87 & Western liquors (vodka, brandy) & 0.000 & & 0.00 & & 0.000 & & 0.00 & & 0.000 & & 0.00 & \\
\hline 88 & Wine & 0.000 & & 0.00 & & 0.000 & & 0.00 & & 0.000 & & 0.00 & \\
\hline 89 & Makgeolli (unrefined rice wine) & 0.000 & & 0.00 & & 0.000 & & 0.00 & & 0.000 & & 0.00 & \\
\hline \multicolumn{14}{|c|}{ Bread and snacks } \\
\hline 12 & Doughnut & 0.000 & & 0.00 & & 0.000 & & 0.00 & & 0.000 & & 0.00 & \\
\hline 13 & Bread 1 (cream bun, muffin) & 0.005 & & 0.33 & & 0.000 & & 0.33 & & 0.000 & & 0.08 & \\
\hline 14 & Bread 2 (bread rolls, garlic bread) & 0.008 & & 0.45 & & 0.000 & & 0.50 & & 0.000 & & 0.10 & \\
\hline 15 & Cakes & 0.004 & & 0.20 & & 0.000 & & 0.83 & & 0.000 & & 0.03 & \\
\hline 90 & Chocolate & 0.000 & & 0.00 & & 0.000 & & 0.00 & & 0.000 & & 0.00 & \\
\hline
\end{tabular}


Table 3. Number of dishes contributing to seventeen nutrients with up to 90 cumulative percentage contribution (cPC) and 0.9 cumulative multiple regression coefficient (CMRC) from the model with ninety-five dishes

\begin{tabular}{lcc}
\hline Nutrients & cPC & cMRC \\
\hline Energy & 66 & 39 \\
Protein & 64 & 36 \\
Fat & 67 & 31 \\
Carbohydrate & 36 & 19 \\
Fibre & 52 & 28 \\
Ca & 63 & 26 \\
P & 62 & 40 \\
Fe & 71 & 34 \\
Na & 70 & 29 \\
K & 61 & 41 \\
Vitamin A & 68 & 12 \\
Retinol & 72 & 1 \\
$\beta$-Carotene & 57 & 17 \\
Vitamin $\mathrm{B}_{1}$ & 55 & 25 \\
Vitamin $\mathrm{B}_{2}$ & 63 & 39 \\
Niacin & 59 & 31 \\
Vitamin C & 33 & 8 \\
\hline
\end{tabular}

with previous developed FFQ in $\operatorname{Korea}^{(11,17,18)}$ and other countries $^{(4,9,10,22)}$.

The main reduction from the initial 993 dishes compiled in the $24 \mathrm{~h}$ recall to the ninety-five dishes in the FFQ resulted from aggregating 359 items to ninety-five usable dishes in the last step. Therefore, there was a minimal loss of information, but all the nutrients provided by 359 foods and dishes remained in the calculation. The regression analysis resulted in the greatest reduction in the number of items ( $87 \%$ reduction to 359 items) as compared with the contribution analysis (65\% reduction to 411 items). The number of dish items that covered $90 \%$ of the total nutrients consumed by the study subjects varied from thirty-three items for vitamin $\mathrm{C}$ to seventy-two items for retinol. To test the function of ranking individuals using the DFFQ, cumulative regression coefficients were estimated. As a result, the top twenty dish items among the ninety-five items accounted for 67 to $100 \%$ of the between-person variation of the main

Table 4. Percentage coverage and cumulative multiple regression coefficient (cMRC) of the total population intake of seventeen nutrients by the selected ninety-five dish items

\begin{tabular}{lcc}
\hline Nutrients & Coverage $(\%)$ & CMRC $\left(R^{2}\right)$ \\
\hline Energy & 92.3 & 0.9971 \\
Protein & $92 \cdot 2$ & 0.9997 \\
Fat & 91.2 & 0.9959 \\
Carbohydrate & $95 \cdot 2$ & 0.9983 \\
Fibre & $93 \cdot 2$ & 0.9999 \\
Ca & $92 \cdot 1$ & 0.9999 \\
$\mathrm{P}$ & 93.0 & 0.9996 \\
$\mathrm{Fe}$ & 91.5 & 0.9999 \\
$\mathrm{Na}$ & 90.5 & 1.0000 \\
$\mathrm{~K}$ & 92.8 & 0.9872 \\
Vitamin A & 90.5 & 1.0000 \\
Retinol & 88.6 & 1.0000 \\
$\beta$-Carotene & 90.7 & 1.0000 \\
Vitamin $\mathrm{B}_{1}$ & 94.3 & 0.9997 \\
Vitamin $\mathrm{B}_{2}$ & 92.6 & 0.9998 \\
Niacin & 93.1 & 0.9998 \\
Vitamin C & 95.4 & 1.0000 \\
\hline
\end{tabular}


seventeen nutrients consumed by the entire study subject population. Each nutrient composition defined the number of dish items required to meet an underestimation factor of less than $10 \%$. Some micronutrients, including retinol and vitamin $\mathrm{C}$, had a limited number of dish items accounting for more than $90 \%$ of the between-person variation in intake, and were assessed relatively easily via a small number of items in the DFFQ. In contrast, thirty-one to thirty-nine items were needed to reach the $90 \%$ level for the between-person variation in energy, protein and fat intake, which is similar to other studies ${ }^{(9,12,23)}$. Even some items with a limited amount of specific nutrients may still be effective in discriminating between individuals. In this population, grilled fatty fish accounted for $96 \%$ of the between-person variability in retinol intake, but only contributed $17.9 \%$ of the total retinol intake, indicating that this dish was not a major contributor of retinol. However, this explained a relatively large amount of the variability within populations. As for vitamin $\mathrm{C}$ intake, only eight items were needed to account for over $90 \%$ of the between-person variability.

The cPC estimation results imply that there are limited dish and food sources for some nutrients such as vitamin $\mathrm{C}$ and carbohydrate in the Korean diet, whereas there is a variety of dish and food sources for other nutrients such as fat and retinol. Therefore, the length of the dish list used during the development of a DFFQ could depend on a nutrient of interest in relation to a disease.

The present study has several limitations originating from the KNHANES data we used. First, the use of the single day $24 \mathrm{~h}$ dietary recall meant that it was not possible to estimate within-person variations. Second, seasonal variation of food was not included in the survey of the 2001 KNHANES, as it was conducted from November through December. For example, the contributions of fruits more readily available during the survey period might be overestimated, and the contributions of other fruits that were less available might be underestimated. Therefore, several seasonal food items, for example, seasonal fruits (strawberry, watermelon, etc) and celebration foods not covered by the survey period of the 2001 KNHANES were included in the DFFQ, taking into consideration the seasonal variation of the Korean diet.

In conclusion, the selected ninety-five dish items that were included in the DFFQ covered $90 \%$ of the total seventeen nutrients consumed by subjects, as well as $99 \%$ of the between-person variation for the nutrients of interest. Therefore, the ninety-five selected items could be useful in developing a DFFQ for use in large-scale epidemiological studies of Koreans, within less than $10 \%$ underestimation.

\section{Acknowledgements}

The present study was supported in part by a Korea Science and Engineering Foundation (KOSEF) grant funded by the Korean government (MOST) (no. R01-2006-00010621-0). The authors declare that there are no potential conflicts of interest. The authors' responsibilities were as follows: K. M. K. designed the study and obtained funding; Y. O. K., S.-A. L. and K. M. K. contributed to the study design, interpretation of the results and manuscript preparation; S. S. contributed to the study design and interpretation of the results; Y. M. Y. carried out the statistical analysis of data. All authors approved the final manuscript.

\section{References}

1. Kim S, Moon S \& Popkin BM (2000) The nutrition transition in South Korea. Am J Clin Nutr 71, 44-53.

2. Yoo KY, Shin HR, Chang SH, Choi BY, Hong YC, Kim DH, Kang D, Cho NH, Shin C \& Jin YW (2005) Genomic epidemiology cohorts in Korea: present and the future. Asian Pac $J$ Cancer Prev 6, 238-243.

3. Andersen LF, Veierod MB, Johansson L, Sakhi A, Solvoll K \& Drevon CA (2005) Evaluation of three dietary assessment methods and serum biomarkers as measures of fruit and vegetable intake, using the method of triads. $B r J$ Nutr 93, 519-527.

4. Pellegrini N, Salvatore S, Valtuena S, et al. (2007) Development and validation of a food frequency questionnaire for the assessment of dietary total antioxidant capacity. J Nutr 137, 93-98.

5. Willett WC (1998) Food-frequency methods. In Nutritional Epidemiology, pp. 74-100. Oxford: Oxford University Press.

6. Block G, Woods M, Potosky A \& Clifford C (1990) Validation of a self-administered diet history questionnaire using multiple diet records. J Clin Epidemiol 43, 1327-1335.

7. Cade J, Thompson R, Burley V \& Warm D (2002) Development, validation and utilisation of food-frequency questionnaires - a review. Public Health Nutr 5, 567-587.

8. Willett WC, Sampson L, Stampfer MJ, Rosner B, Bain C, Witschi J, Hennekens CH \& Speizer FE (1985) Reproducibility and validity of a semiquantitative food frequency questionnaire. Am J Epidemiol 122, 51-65.

9. Tsubono Y, Takamori S, Kobayashi M, Takahashi T, Iwase Y, Iitoi Y, Akabane M, Yamaguchi M \& Tsugane S (1996) A databased approach for designing a semiquantitative food frequency questionnaire for a population-based prospective study in Japan. J Epidemiol 6, 45-53.

10. Date C, Fukui M, Yamamoto A, et al. (2005) Reproducibility and validity of a self-administered food frequency questionnaire used in the JACC study. J Epidemiol 15, Suppl. 1, S9-S23.

11. Kim MK, Lee SS \& Ahn YO (1996) Reproducibility and validity of a self-administered semiquantitative food frequency questionnaire among middle-aged men in Seoul. Korean $J$ Community Nutr 1, 376-394.

12. Ahn Y, Lee JE, Paik HY, Lee HK, Jo I \& Kim K (2003) Development of a semi-quantitative food frequency questionnaire based on dietary data from the Korea National Health Examination Survey. Nutr Sci 6, 173-184.

13. Ministry of Health and Welfare (2002) Report on 2001 National Health and Nutrition Survey. Seoul: Ministry of Health and Welfare.

14. Kim MK, Lee JY \& Kim Y (2005) Effects of alcohol consumption to blood lipids among Korean adults: the 2001 Korean National Health and Nutrition Examination Survey. Cancer Prev Res 10, 159-165.

15. Rural Nutrition Institute \& Rural Development Administration (2001) Food Composition Tables, 6th revision, Soeul: Rural Nutrition Institute, The Government of the Republic of Korea.

16. Korea Health Industry Development Institute and Ministry of Health and Welfare (2000) Development of Nutrient Database, Recipe, and Portion Size. Seoul: Korea Health Industry Development Institute and Ministry of Health and Welfare.

17. Kim J, Kim Y, Ahn YO, Paik HY, Ahn Y, Tokudome Y, Hamajima N, Inoue M \& Tajima K (2003) Development of a food frequency questionnaire in Koreans. Asia Pac J Clin Nutr 12, 243-250. 
18. Lee HJ, Lee HS, Ha MJ, Kye SH, Kim CI, Lee CW \& Yoon JS (1997) The development and evaluation of a simple semiquantitative food frequency questionnaire to assess the dietary intake of adults in large cities. Korean J Community Nutr 2, 349-365.

19. Ahn Y, Kwon E, Shim JE, Park MK, Joo Y, Kimm K, Park C \& Kim DH (2007) Validation and reproducibility of food frequency questionnaire for Korean genome epidemiologic study. Eur J Clin Nutr 61, 1435-1441.

20. Korean Ministry of Health and Welfare (1996) Report on National Nutrition Survey 1995. Seoul: Korean Ministry of Health and Welfare.
21. Shim JE, Paik HY, Moon HK \& Kim YO (2001) Comparative analysis and evaluation of dietary intake of Korean by age group: (1) nutrient intakes. Korean J Nutr 34, 554-567.

22. Keating GA, Bogen KT \& Chan JM (2007) Development of a meat frequency questionnaire for use in diet and cancer studies. J Am Diet Assoc 107, 1356-1362.

23. Shahar D, Shai I, Vardi H, Brener-Azrad A \& Fraser D (2003) Development of semi-quantitative food frequency questionnaire (FFQ) to assess dietary intake of multiethnic population. Eur $J$ Epidemiol 18, 855-861. 
Appendix

Sample questionnaire for staple food in a developed dish-based food-frequency questionnaire.

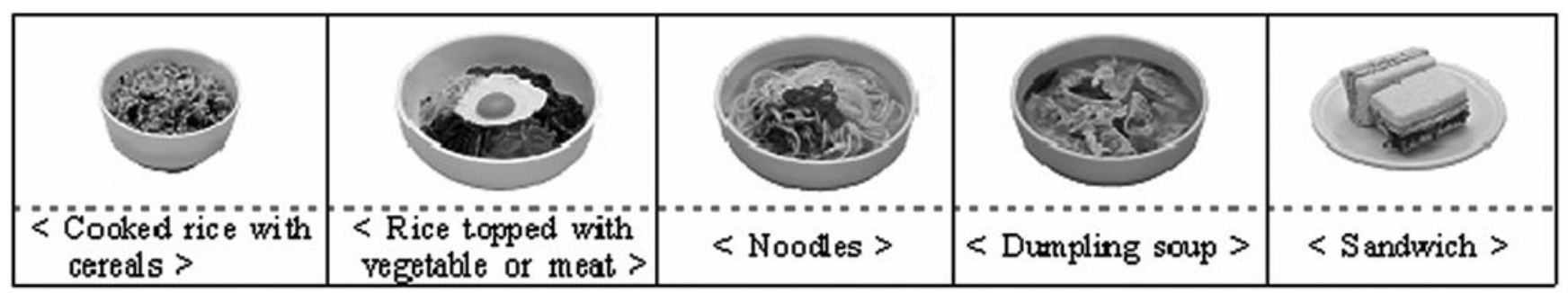

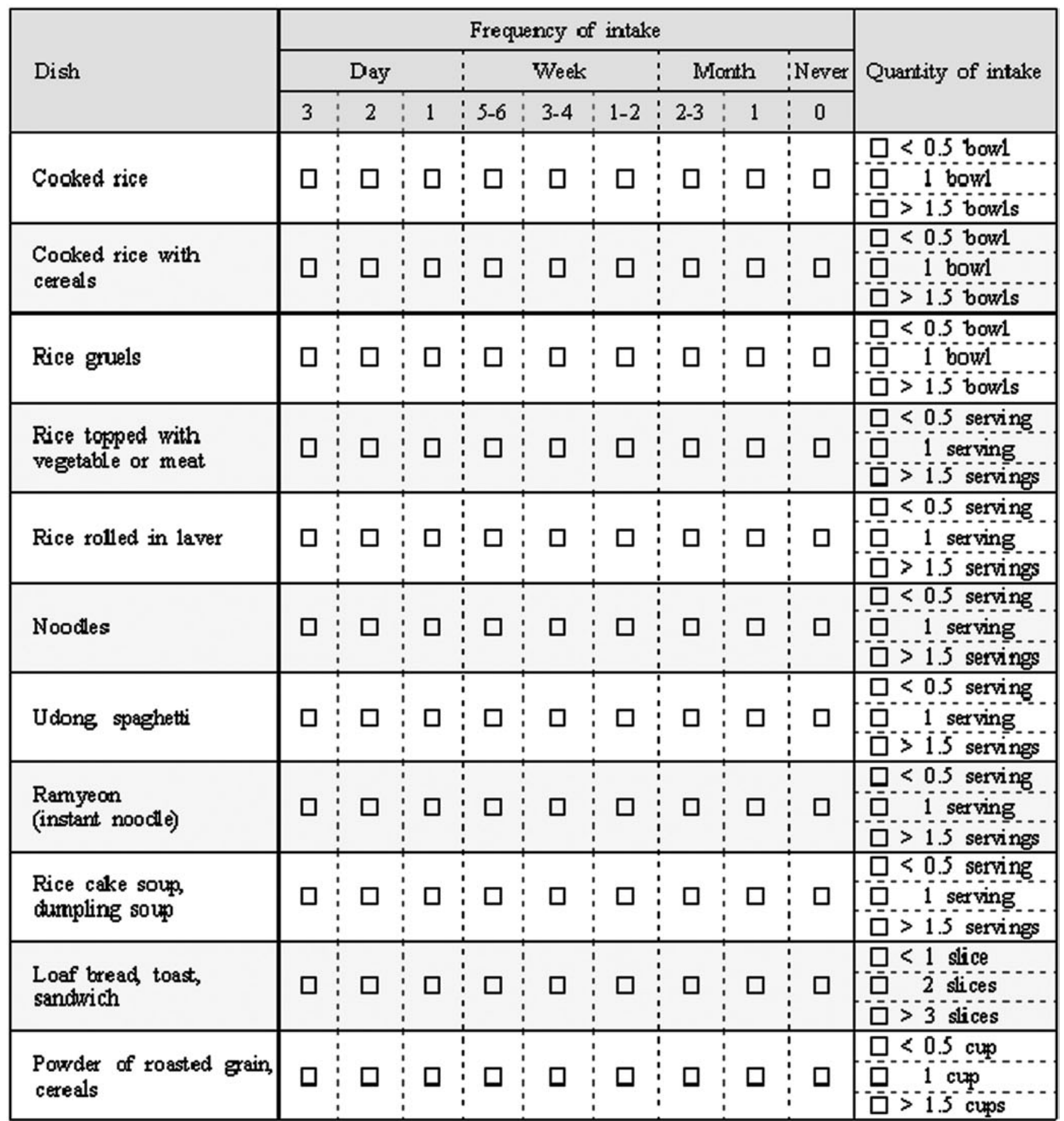

